\title{
ASSESSMENT OF OPERABILITY OF COMPRESSOR CRANKSHAFT
}

\author{
Alexander Pastukhov, Aleksandr Kolesnikov, Dmitriy Bakharev, Irina Berezhnaya \\ Belgorod State Agricultural University named after V. Gorin, Russia \\ pastukhov_ag@mail.ru, a.c.kolesnikov@mail.ru,baharevdn_82@mail.ru,fajzir@yandex.ru
}

\begin{abstract}
Results of assessment of operability of the crankshaft of the K05-12 compressor installed in the Maxima 1000/1300 refrigeration unit on the Volvo cars are provided. As a criterion of refusal sudden physical destruction of the console site of the two-piece line crankshaft in a zone of a belt drive sheave at an early stage of operation is accepted. As a result of researches the microstructural analysis of material of original and replacement crankshafts is carried out, the rated scheme taking into account geometrical parameters of a part under the influence of operational loadings at an adverse combination to a static tension is made, analytical assessment of durability of the crankshaft is executed, the graphic 3D-model of a part executed by means of CAD-technology of the computer-aided engineering system COMPAS 3D is received. For the purpose of automation and increase in productivity and reliability of rated assessment of durability and rigidity of the crankshaft, test calculations are executed on the basis of CAE-technology by means of the computer-aided engineering system automated workplace APM WinMachine in the APM Studio automated workplace rated module. In the course of assessment comparative calculations of parameters of durability and rigidity at production of crankshafts are made of the VCh 40 high-strength cast iron (a replacement part) and VCh 70 (an original part), when performing fillets in a zone of destruction of a shaft on radius $0.5 ; 1.0$ and $2.0 \mathrm{~mm}$ and also at the modes of normal and extreme operational loading. The end results were estimated in sizes of equivalent normal stresses from a bend and torsion, total linear movement, reserve factor on the flowability, static and fatigue resistance, quantity of cycles before fatigue failure. As a result of calculations emergency conditions of loading and basic reasons of failure of the crankshaft by physical destruction are established.
\end{abstract}

Keywords: operability, crankshaft, failure, loading, assessment.

\section{Introduction}

In the practice of the study of reliability of technical systems the concept of efficiency and failure is widely used. Under operability is understood the state of the technical object, in which it is able to perform specified functions. Transition from operating state to disabled is characterized by the approach of the event called by refusal, at which there is a full loss of operability of an object. Often, when operating auxiliary equipment of transport and technological machines, for example, vehicles with refrigeration units, there are situations associated with the manifestation of sudden catastrophic failures of parts of compressor machines, in particular, the physical destruction of the crankshaft $[1 ; 2]$.

The main factors that have a significant impact on the performance of machine parts are: design (material, its mechanical properties, design features, geometric parameters, etc.), technological (modes of mechanical, thermal and other types of processing) and operational (loading modes, quality of maintenance and repair, etc.) [3].

In assessing the performance and identifying the possible causes of catastrophic failure of machine parts, the following types of research are carried out: macro- and microstructure analysis - in order to establish the brand of the material used, measurement of hardness - for a preliminary assessment of the mechanical properties of the material, calculations of stress-strain state - in the study of the impact of operating conditions and structural and technological factors on the strength and rigidity of machine parts.

The object of the study - two-piece inline crankshaft of the compressor K05-12 installed in a refrigeration unit of Maxima 1000/1300 cars-refrigerated trucks Volvo.

The subject of the research - study of the influence of the mechanical characteristics of the material, structural and technological factors, modes of operational loading and the magnitude of the static tension of the belt drive on the strength and stiffness of the crankshaft.

The purpose of the work - to assess the efficiency of the compressor crankshaft K05-12 in terms of strength and stiffness under operational loading.

To achieve this goal it is necessary to solve the following tasks:

1. make a graphical 3D-model of the crankshaft; 
2. carry out microstructural studies of the original material and replacement parts with hardness measurement;

3. carry out researches of the stress-strain state of the crankshaft on the parameters of durability and rigidity in the conditions of operational loading.

\section{Materials and methods}

The general view of the row two-section crankshaft is given in Fig. 1. The shaft is made of cast iron with subsequent machining of the main and connecting rods, the right cantilever section with a cone end and a keyway for the installation of the belt drive pulley, as well as the left cantilever section with the end structural elements for the drive of the oil pump.

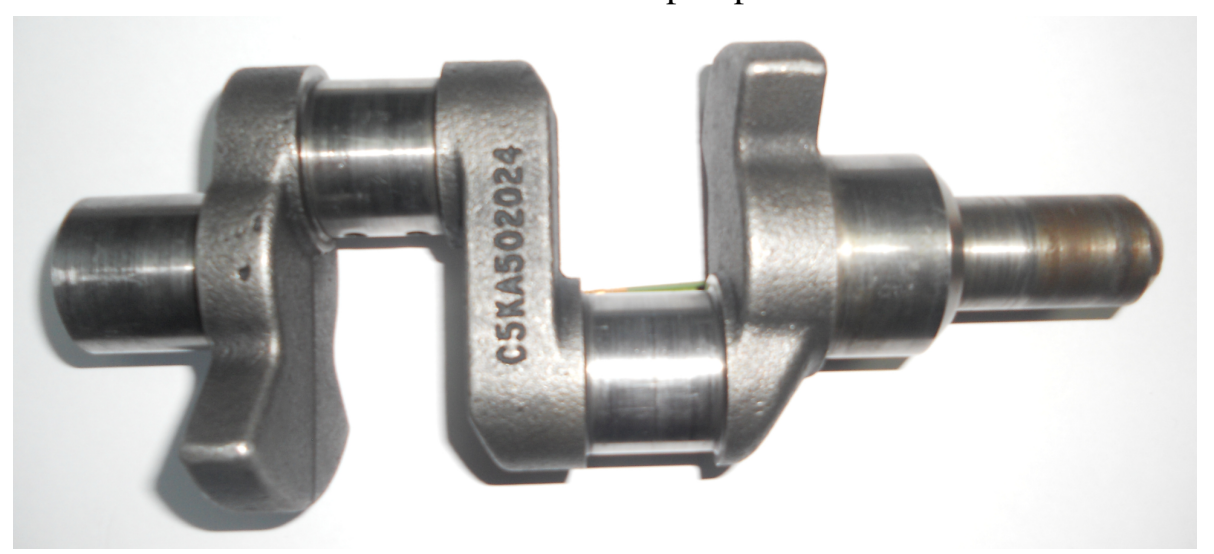

Fig. 1. General view of crankshaft

The result of the metric evaluation of the crankshaft using a vernier calliper ShC-I-250-0,05 GOST 166-89 set geometric parameters of the structural elements identified the dimensions between the characteristic cross-sections for the compilation of the design diagram of the crankshaft, determined the diameters of the journals to calculate geometrical characteristics of cross-sections and constructed a 3D graphical model (Fig. 2) for the subsequent numerical analysis.

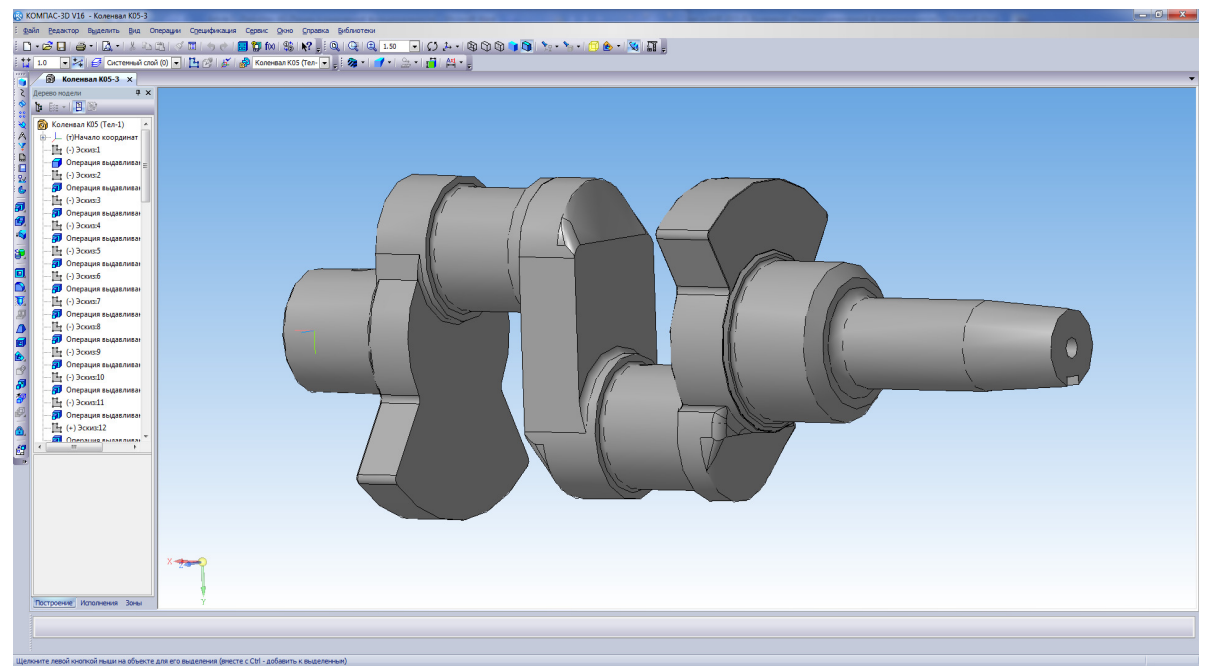

Fig. 2. 3D-model of crankshaft

Due to the lack of technical documentation and data on the material of the original and replacement crankshafts, the microstructure analysis was carried out with the help of metallographic inverted microscope "Micromed MET" with a multiplicity of magnification to $\times 100$, sample sanding (Fig. 3) in the area of the cantilever end with the purpose of establishing the type and brand of cast iron and measuring the hardness of Brinell through a stationary hardness tester TSh-2M for the establishment of the real mechanical characteristics. 


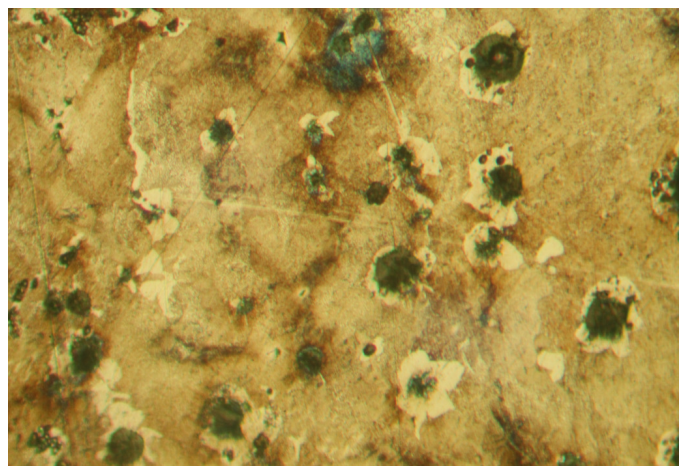

a)

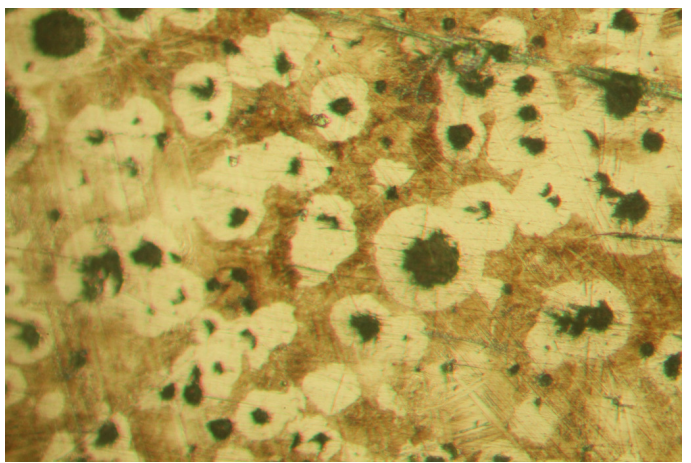

b)

Fig. 3. Images of cast-iron microstructures: a - sample No.1, form, diameter and number of inclusions ShGf5, ShGd45, ShG4, content of perlite and ferrite P85(F15) in accordance with GOST 3443-87 (ISO 945-75); b - sample No. 2, similarly - ShGf5, ShGd45, ShG6, P45(F55)

Image analysis of the microstructure of thin sections (Fig. 3) allows to claim that crankshafts are made of high-strength ferrite-perlite cast iron with spherical graphite of the VCh GOST 7293-85. Measurements of hardness of samples No. 1 and 2, respectively, showed that the original crankshaft with an average hardness of HB 264 is manufactured of high-strength cast iron possibly of the VCh 70 brand (EN-GLS-700-2, EN-JS1070), and the replacement crankshaft with an average hardness of HB 168 is manufactured of high-strength cast iron possibly of the VCh 40 brand (EN-GLS-400-15, EN-JS1030). The higher hardness of sample No. 1 compared to the hardness of sample No. 2 is confirmed by the microstructure of samples, as the perlite inclusion of the metal base of sample No. 1 is comparatively greater, which eventually increases the hardness of cast iron. Thus, we have established the mechanical characteristics of the material crankshaft: the original shaft is made of the VCh 70 brand with a limit of tensile strength $\sigma_{u t}=700 \mathrm{MPa}$, conventional yield strength $\sigma_{02}=420 \mathrm{MPa}$ and relative elongation of $\varepsilon=2 \%$ and replacement the shaft is made of the VCh 40 brand with a limit of tensile strength $\sigma_{u t}=400 \mathrm{MPa}$, conventional yield strength $\sigma_{02}=250 \mathrm{MPa}$ and relative elongation of $\varepsilon=15 \%$ [4].

The mode of operational loading of the crankshaft of the K05-12 two-cylinder compressor is defined by power setting of ST4-91 of the Maxima 1000/1300 refrigeration unit. On the basis of a technical characteristic of units we establish the following basic data: engine shaft power $N_{\mathrm{n}}=15.5 \mathrm{~kW}$ (21 h.p.), shaft speed of the engine $-n=1900 \mathrm{~min}^{-1}$; pressure in over the piston of the compressor $-p_{1}=30 \mathrm{Bar}(3.0 \mathrm{MPa})$, pressure in subpiston space $-p_{2}=2 \mathrm{Bar}(0.2 \mathrm{MPa})$, average diameter of the piston $-D_{\mathrm{p}}=50.57 \mathrm{~mm}$, connecting rod length $-L=107 \mathrm{~mm}$, crank radius $r=24.6 \mathrm{~mm}$; parameters of the belt drive: full length of a belt $-l_{\mathrm{p}}=1390 \mathrm{~mm}$, sizes of lateral section - $17 \times 11 \mathrm{~mm}$, sectional area $-A=138 \mathrm{~mm}^{2}$, diameter of a driving pulley $-d_{1}=96 \mathrm{~mm}$, diameter of a driven pulley $-d_{2}=202 \mathrm{~mm}$, interaxal distance $-a_{\omega}=309 \mathrm{~mm}$, central corner of branches of transfer $-\beta=19.6^{\circ}$, running mass of a belt $-k=0.175 \mathrm{~kg} \cdot \mathrm{m}^{-1}$, transfer branch length $-l=314 \mathrm{~mm}$, rated and maximum frequency of vibrations of a belt $-f_{\mathrm{n}}=67 \mathrm{~Hz}$ and $f_{\max }=140 \mathrm{~Hz}$, number of belts in transfer $-Z=2[5 ; 6]$.

Calculation of a torsion torque, radial and tangential forces in the mechanism of the compressor is carried out by the following technique.

Rated torsion torque $T_{\mathrm{n}}, \mathrm{Nm}$ on a shaft of the engine we determine by formula [1-3]

$$
T_{n}=9550 \cdot N_{n} / n,
$$

where $N_{\mathrm{n}}$ - engine power, $\mathrm{kW}$

$n$-shaft speed of the engine, $\min ^{-1}$.

Resultant force $F_{\text {Comp }}, N$, we determine pressure of gases upon the piston by formula [1-3]

$$
F_{\text {Comp }}=p_{\text {Comp }} \cdot \pi D_{\mathrm{p}}^{2} / 4
$$

where $p_{\text {Comp }}=p_{1}-p_{2}-$ calculated pressure in the compressor, $\mathrm{MPa}$; 
$p_{1}$ - pressure in over the piston of the compressor, $\mathrm{MPa}$;

$p_{2}$ - pressure in subpiston space, $\mathrm{MPa}$;

$D_{p}$ - diameter of the piston, $\mathrm{mm}$.

At the maximum value of a torsion torque on a shaft we determine the force $F_{\text {Con }}, N$, transmitted via the connecting rod by empirical formula $[2 ; 3]$

$$
F_{\text {Con }}=0.65 \cdot F_{\text {Comp }} \text {. }
$$

Then radial $F_{\mathrm{r}}, N$, and tangential $F_{\mathrm{t}}, N$, making efforts are also equal $[2 ; 3]$

$$
\begin{aligned}
& F_{r}=0.5 \cdot F_{\text {Comp }}, \\
& F_{t}=0.4 \cdot F_{\text {Comp }} .
\end{aligned}
$$

The rated torsion torque on a shaft of the compressor is equal $[2 ; 3]$

$$
T_{\text {Comp }}=F_{t} \cdot r \text {. }
$$

The size of the force of a static tension $F_{\mathrm{S}}, N$, in the belt gear of the drive of the parking generator we determine by the recommendations of the producer by formula $[5 ; 6]$

$$
F_{S t}=4 \cdot k \cdot l^{2} \cdot f^{2},
$$

where $k$-running mass of a belt, $\mathrm{kg} \cdot \mathrm{m}^{-1}$;

$l$ - length of a branch of the belt gear, $\mathrm{m}$;

$f$ - frequency of vibrations of a belt, $\mathrm{Hz}$.

We determine the console loading $F_{\mathrm{K}}, N$, operating on the compressor crankshaft in an installation site of a belt drive sheave by formula [7]

$$
F_{K}=Z \cdot 2 F_{S t} \cdot \cos \beta / 2,
$$

where $\mathrm{Z}$ - number of belts.

\section{Results and discussion}

On the basis of the basic data given above, using formulas (1) - (8), we receive values of the parameters of loading of the crankshaft of the compressor: $T_{\mathrm{n}}=77.9 \mathrm{Nm}, \quad F_{\text {Comp }}=5620 \mathrm{~N}$, $F_{\text {Con }}=3650 N, \quad F_{\mathrm{r}}=2810 N, \quad F_{\mathrm{t}}=2250 \mathrm{~N}, \quad T_{\text {Comp }}=55.1 N m, \quad F_{\mathrm{St}}=310 N, \quad F_{\mathrm{St}} \max =1350 N, \quad F_{\mathrm{K}}$ $\mathrm{n}=1220 \mathrm{~N}, F_{\mathrm{K} \max }=5320 \mathrm{~N}$.

The theoretical basis of calculations on the static durability, fatigue resistance taking into account the influence of constructive technology factors and rigidity is made by provisions of the theory of strength of materials and calculation of parts of cars [7; 8; 9]. However, for the purpose of automation, increase in productivity and increase in reliability of rated assessment of durability and rigidity of the K05-12 crankshaft it is feasible to do the mentioned calculations in the environment APM WinMachine in modules APM Studio and an APM Structure 3D [10]. On a 3D model of the crankshaft we make its rated scheme by import through the *.stp format in the rated module. We establish support in the place of radical necks, loadings taking into account distribution on the area on rod journals and longwise the console end, we choose the material and we create a final element 4 th nodal tetrahedral grid.

For input of the basic data in the rated scheme it is necessary to execute their preparation:

- $\quad$ area $1 / 4$ crankpin $A_{\mathrm{ss}}=\pi d l / 4=3,14 \cdot 34,9 \cdot 28 / 4=767 \mathrm{~mm}^{2}$;

- specific force distributed on the area for radial and district forces: $F_{\mathrm{r}} / A_{\mathrm{ss}}=2810 / 767=3.67 \mathrm{~N} \cdot \mathrm{mm}^{-2}, F_{\mathrm{t}} / A_{\mathrm{ss}}=2250 / 767=2.93 \mathrm{~N} \cdot \mathrm{mm}^{-2}$;

- torsion torque in the form of effort of the spline groove distributed longwise on a crankshaft $l=29 \mathrm{~mm}$ with an average diameter $d_{\mathrm{m}}=(25.5+22) / 2=23.75 \mathrm{~mm}$, then at $F_{\mathrm{tp}}=2 T_{\mathrm{Comp}} / d_{\mathrm{m}}=2 \cdot 55.1 /\left(23.75 \cdot 10^{-3}\right)=4640 \mathrm{~N}$, from where $F_{\mathrm{tp}} / l=4640 / 29=160 \mathrm{~N} \cdot \mathrm{mm}^{-1}$;

- $\quad$ area $1 / 2$ of a radical neck $A_{\mathrm{ks}}=\pi d l / 2=3.14 \cdot 23.75 \cdot 29 / 2=1081 \mathrm{~mm}^{-2}$;

- $\quad$ specific force on the area for console force $F_{\mathrm{K}} / A_{\mathrm{ks}}=1217 / 1081=1.13 \mathrm{~N} \cdot \mathrm{mm}^{-2}$. 
The main results of calculation of the parameters of durability and rigidity of the crankshaft taking into account the influence of the radius fillets at the console end and the right radical neck $(\rho=0.5$; $1.0 ; 2.0 \mathrm{~mm}$ ) for two brands of cast iron of an original and replacement part are specified in Table 1.

Diagrams of distribution of values of the reserve factor and number of cycles on fatigue resistance before destruction at $\rho=1.0$ of the shaft made of the VCh 70 brand are given in Fig. 4 and 5.

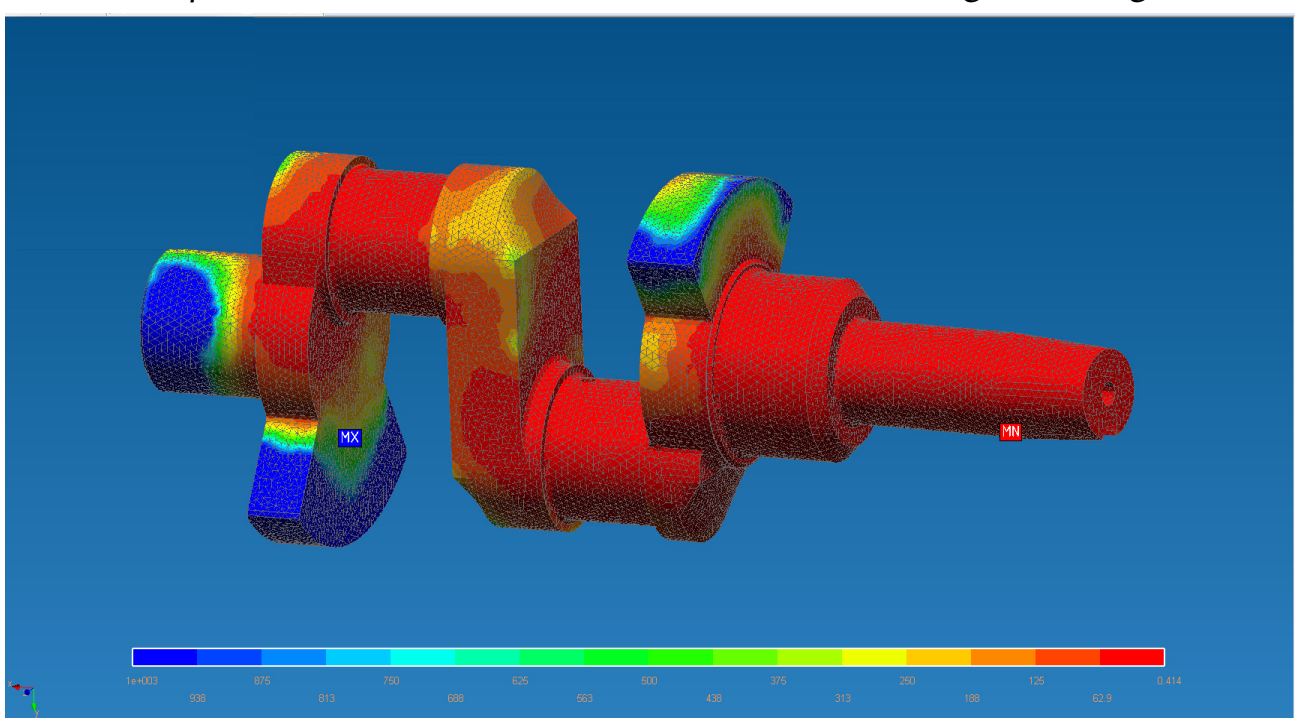

Fig. 4. Diagram of reserve factor on fatigue

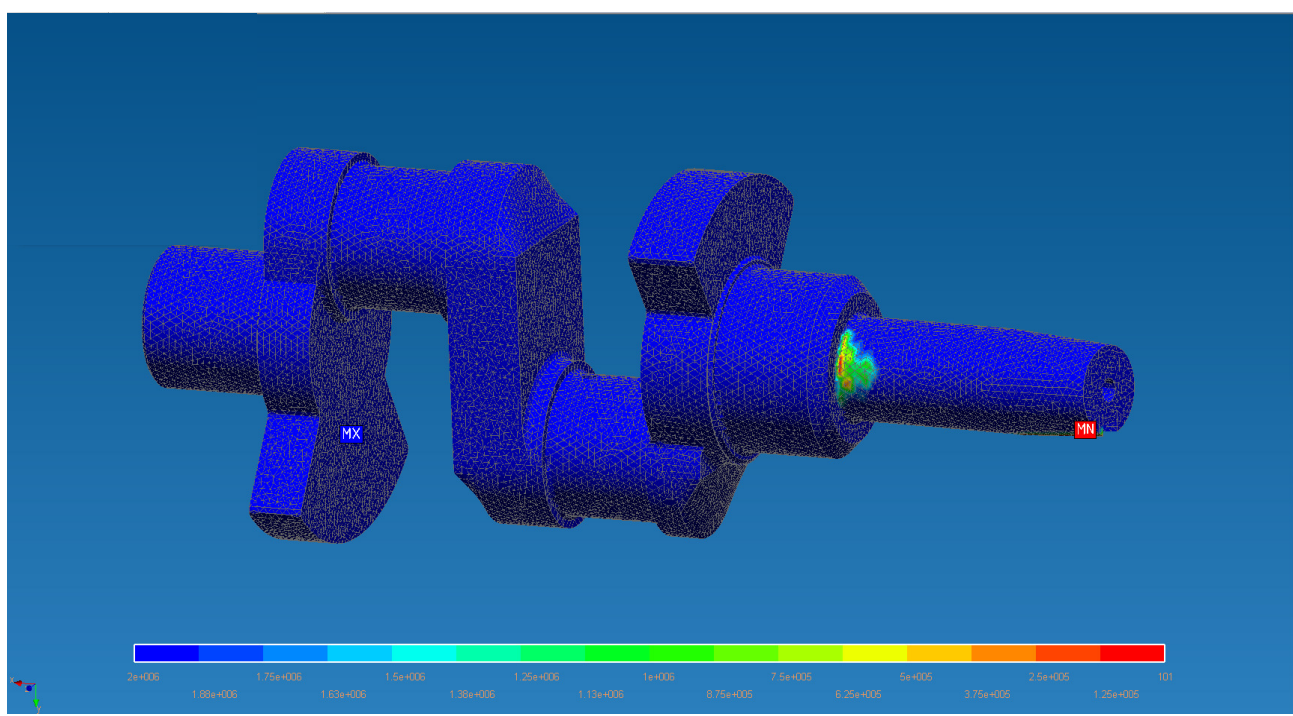

Fig. 5. Diagram of number of cycles before destruction on fatigue

Results of calculations of parameters of durability and rigidity

\begin{tabular}{|l|c|c|c|c|}
\hline \multicolumn{1}{|c|}{ Parameters } & $\begin{array}{c}\boldsymbol{\rho}=\mathbf{0 . 5} \\
\mathbf{m m}, \\
\text { VCh 40 }\end{array}$ & $\begin{array}{c}\boldsymbol{\rho = 1 . 0} \\
\mathbf{m m}, \\
\text { VCh 40 }\end{array}$ & $\begin{array}{c}\boldsymbol{\rho = 2 . 0} \\
\mathbf{m m}, \\
\text { VCh 40 }\end{array}$ & $\begin{array}{c}\boldsymbol{\rho = 1 . 0} \\
\mathbf{m m}, \\
\text { VCh 70 }\end{array}$ \\
\hline Equivalent tension according to Mises, MPa & 329 & 328 & 329 & 328 \\
\hline Total linear movement, mm & 0.280 & 0.269 & 0.273 & 0.269 \\
\hline Reserve factor on flowability & 2.83 & 2.84 & 2.83 & 3.90 \\
\hline Reserve factor on durability & 4.26 & 4.27 & 4.26 & 6.10 \\
\hline Reserve factor on fatigue & 0.252 & 0.275 & 0.312 & 0.414 \\
\hline Number of cycles on fatigue, min & 39.8 & 28.4 & 25.7 & 101 \\
\hline Principal strength, MPa & 270 & 235 & 231 & 235 \\
\hline
\end{tabular}


The greatest total linear movement of the end of the shaft is equal to $0.280 \mathrm{~mm}$. Static durability of the shaft is provided with a reserve factor on flowability $-2.83-3.90$, durabilities $-4.26-6.10$.

\section{Conclusions}

1. As a result of analytical calculation on durability of the K05-12 crankshaft made at the VCh 40 brand under operating conditions at the rated modes, we note that the reserve factor of static durability meets the condition of durability (more than 2.5), however the reserve factor of fatigue resistance (1.977) taking into account the influence of constructive technology factors demonstrates impossibility of providing $100 \%$ of probability of operability of the crankshaft (at the level of 2.5) and tendencies to brittle destruction in zone fillets at an operating time below the basic number of cycles of change of tension (26-40 cycles).

2. Durability assessment of a possibility of destruction of the crankshaft in zone leads fillets at the console end at increase in the force of a static tension of the belt gear of the drive to decrease in the reserve factor of fatigue resistance below unit $(0.51)$ that testifies to a possibility of brittle destruction both for the crankshaft made at the VCh 40 brand, and for the crankshaft made at the VCh 70 brand; at the same time the level of providing $100 \%$ of probability of operability of the crankshaft (at reserve factor 2.5) on the force of a static tension of $277 \mathrm{~N}$ is below the limit recommended by the manufacturer of $309 \mathrm{~N}$.

3. Calculations for assessment of durability and rigidity of the crankshaft made at the VCh 40 brand at variation of the radius fillets in dangerous section $\rho=0.5 ; 1.0 ; 2.0 \mathrm{~mm}$ showed that the parameters of static and fatigue resistance and rigidity practically do not change.

4. Operation of the crankshaft on fatigue is characterized by the difficult mode of loading at a bend with torsion, in this regard the coefficient of margin of safety on fatigue is not high 0.252-0.312 at the number of cycles of work 25.7-39.8 that is caused by low mechanical characteristics at the VCh 40 brand cast iron. Similar calculation for the crankshaft made at the VCh 70 brand cast iron showed increase in the reserve factor on fatigue for 48 , and the numbers of cycles of work - by 3.2 times.

\section{References}

[1] Compressor handbook / Paul C. Hanlon, editor. New York: McGraw-Hill Companies, 2001.754p.

[2] Пластинин П.И. Поршневые компрессоры. Том 1. Теория и расчет. М.: КолосС, 2006. 456 с. (Plastinin P.I. Piston compressors. Thom 1. Theory and calculation. M.: ColosS, 2006. 456 p.) (In Russian)

[3] Bloch H.P., Hoefner J.J. Reciprocating compressors: operation and maintenance. Houston: Gulf Professional Publishing, 1996. 407 p.

[4] ГОСТ 7293-85 Чугун с шаровидным графитом для отливок. (GOST 7293-85 Spheroidal graphite iron for castings. Grades) (In Russian)

[5] Service Parts List. Compressor Model 05K. Carrier Refrigeration Operation 2010. Emprime en France 10-10. $20 \mathrm{p}$.

[6] Service Parts List. CT4-91TV for MAXIMA. Carrier Corporation 1999 - source US 62-02460-02. Printed in France 10-99. 53 p.

[7] Колпаков А.П., Карнаухов И.Е. Проектирование и расчет механических передач. М.: Колос, 2000. 328 с. (Kolpakov A.P., Karnaukhov I.E. Design and calculation of mechanical gears. M.: Colos, 2000. 328 p.) (In Russian)

[8] Костенко Н.А., Балясникова С.В., Волошановская Ю.Э. и др. Сопротивление материалов: учеб. пособие / Под ред. Н.А. Костенко. М.: Высшая школа, 2007. 488 с. (Kostenko N.A., Balyasnikova S.V., Voloshanovskaya Yu.E., etc. Strength of materials: studies a grant / Under the editorship of N.A. Kostenko. M.: Higher school, 2007. 488 p.) (In Russian)

[9] Compressed air manual. $7^{\text {th }}$ edition. Atlas Copco Airpower NV, 2010. 135 p.

[10] Замрий А.А. Проектирование и расчет методом конечных элементов в среде APM Structure 3D: учебное пособие. М.: Издательство АПМ, 2010. 376 с. (Zamryj A.A. Design and calculation with a finite element method in the environment of Structure 3D APM: manual. M.: APM publishing house, 2010. 376 p.) (In Russian) 